\title{
Designing Aspects and Classification of Bearing Industry Box Handling Apparatus
}

\author{
Zs. TiBA ${ }^{1}$, D. FEKETE-SZǓCS ${ }^{2}$ \\ 1University of Debrecen, Faculty of Engineering, Department of Mechanical Engineering, tiba@eng.unideb.hu \\ ${ }^{2}$ AFT Soft Ltd, fszdani@unideb.hu
}

Abstract. It has been an accepted tendency in the industrial practice since the last third of the 20th Century to decrease the living labour demand of the manufacturing processes. One of the main tools of it is the automation of production. In the design, the construction and the programming of the developed automata, the results of electronics, informatics and mechatronics can be used. All of the scientific fields mentioned above undergo intensive development. By the application of the results achieved in the design of the applications, the monotonous, dangerous and tiresome work not requiring expertise can be assigned to machines. In the longer run, the application of the automata is beneficial also in financial aspect, since the costs of living labour are continuously growing, while that of the mechatronic and technological devices show a rather decreasing tendency. Reliability is also an important aspect. It is well known for everyone that a well-designed and programmed automatic device performs its task without mistakes. If there is any objection or breakdown, on the basis of the currently valid safety technology rules, the machine stops, does not trigger any damage and after its repair, work can be continued.

Keywords: Handling manipulator, guide of axes, rigidity of frame

\section{Introduction}

During the manufacture of roller bearings, one of the important processes is the production of roller elements. Its first technological step is the automatic preparation and the washing of the raw roller manufactured from the wire billet by cold extrusion afterwards, the rollers are subject to heat treatment, grinding and sometimes super finishing. The roller press is integrated with the washer and its operation is fully automated. The produced billet arrives to the collection place on a conveyor belt and it gets into a box. The full boxes are put onto a trolley and they are carried close to the machines and devices performing the further technological processes. The filling of the boxes is automatic and the trolleys are organised into sets of wagons pulled by industrial forklift trucks. The removal of the empty boxes from the trolleys and the replacement of the full boxes onto the trolley have been performed by the manual work of skilled workers. The aim of the development detailed herein is the automation of the loading and the filling of the boxes and the decrease of the need for living labour. This paper describes one of the main subsystems of the manipulator constructed during the development, the axis system of the unit moving the boxes. The other important element of the development, i.e. the design of the mechanism for the filling of the box is not part of this thesis. This 
thesis focuses on the machine design formation of the device and the electronic modules and the programming are not subject to this thesis either.

During the design and development, the aim is the creation of a fully automatic, fault tolerant, long life and low energy consuming automaton which makes possible the release of two unskilled people.

\section{Design requirements issued by the client}

Just to summarise in short, the client gave the following initial data for the development:

- 3D solid body model of the box to be handled and the trolley used for transport with the necessary dimensions. This is shown by the Figure 2.1.

- The mass of the filling quantity of the box to be filled (40 kg). This is necessary due to the consideration of the loads on the axis system of the manipulator.

- The filling time of the box considering the least favourable situation. The least favourable event is related to the largest roller to be produced, since the box is filled in this case within the shortest time (2.5 minutes).

- The time available for the temporary interruption of the material flow of the billets arriving on the conveyor belt (temporary closing of the conveyor belt, 1 minute). The two data above are necessary due to the determination of the stroke time and the planning of the motion profiles of the carriages.

- The time for the removal of the full trolley and the setting of the empty one (min. 10 minutes). This date is significant, as it is decided here whether the manipulator has to handle two empty and/or full trolleys, since in case of one trolley, the time reserve necessary for ensuring the empty trolley, changing the trolleys and the transport of the full trolley is not available.

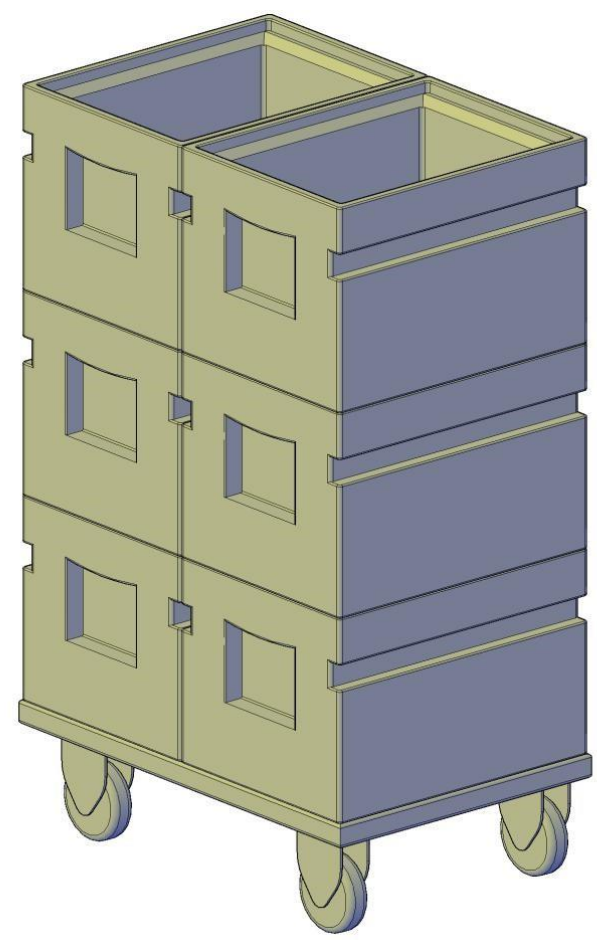

Figure 2.1. Trolley loaded with boxes [7] 


\section{Moving, guiding, fixing parts of the apparatus}

\subsection{Selection of the manipulator}

During the study of the task it became clear that the motions required can be achieved by the "TTT" axis structure manipulator in the simplest, most efficient, fail-safe and relatively cheap way.

The carriages must be able to be moved both horizontally and along the $\mathrm{Z}$ axis and stopped at multiple points. For this we applied among several technical solutions the servo-electric drive.

The servo-electric drives are state-of-the-art technologies and they are considered as well-established, long lifetime and highly reliable solutions. The operational experience of the client is also favourable.

Considering every requirement, this method seems to be optimal for the design of the manipulator, therefore, this is used. The figure below shows an electromechanical toothed belt carriage with the installed drive, axial fitting set and motor:

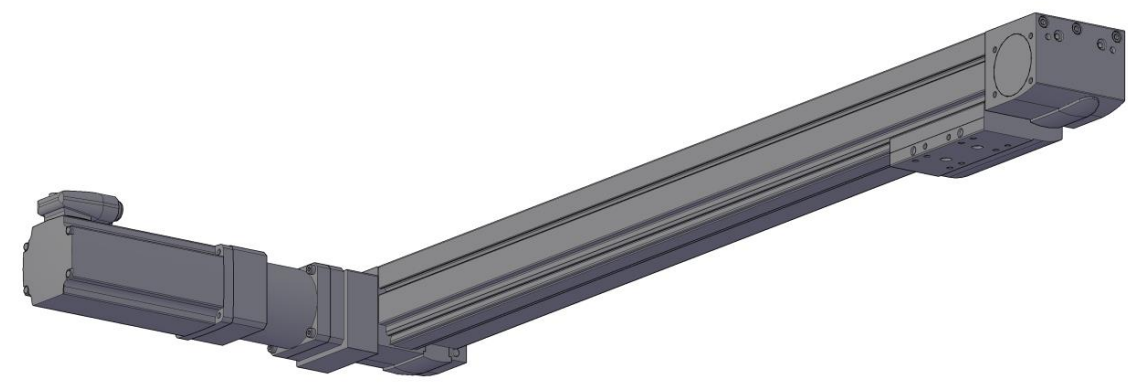

Figure 3.1. EGC toothed belt axis with drive, axial set and three phase motor [3]

\subsection{The guide of the axes}

The applied EGC toothed belt axes can be selected with roller bearing carrier. Due to the longer lifetime, this is applied. Upon the determination of the loads, the torque of the moved load on the carrier regarding the forces of inertia and the weights is a very important aspect.

As the precision to be achieved is in the order of magnitude of millimeters, it is not necessary to use very precise, prestressed and expensive linear cables; the use of the traditional, loosely fit ring-mains and the linear bearing slider is sufficient. Considering all these, all axes are reinforced and led by three ring mains located relatively far from each other. The figure below shows the casing of the $\mathrm{Y}$ axis (holding structure) and the cables integrated into the holder. The figure shows well how the cables with relatively low diameter and applied at the appropriate distance unloads the carriage of the active constraint. 


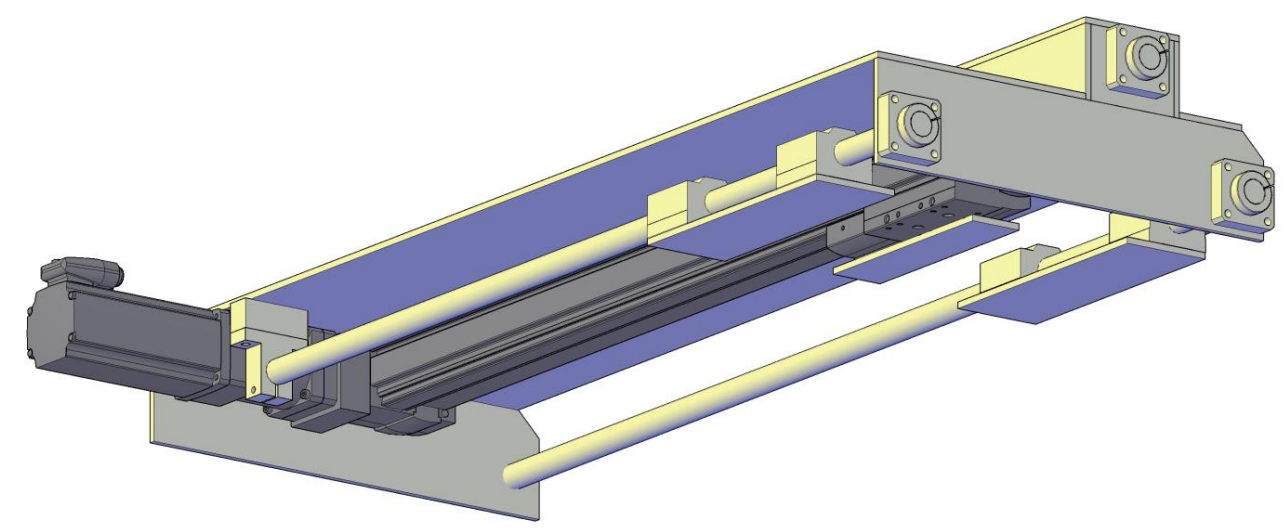

Figure 3.2. The holding structure of the Y axis with the sliders ensuring the displacement of the $Z$ axis.

\subsection{Holding the load, safety technology}

It is the $\mathrm{Z}$ axis to hold the box filled with $40 \mathrm{~kg}$ of rollers and the mechanism for the holding of the box. Their total mass is about $60 \mathrm{~kg}$. Theoretically, the motor is suitable to hold the load at 0 (zero) revolution but application of a pneumatically released brake integrated onto the carriage of the toothed belt axis is a much more favourable solution. The operating principle is similar to the brake integrated into the motor. In case of the outage of compressed air, the system brakes and no accident occurs.

The figure below shows the toothed belt axis with the pneumatic brake installed next to the carriage:

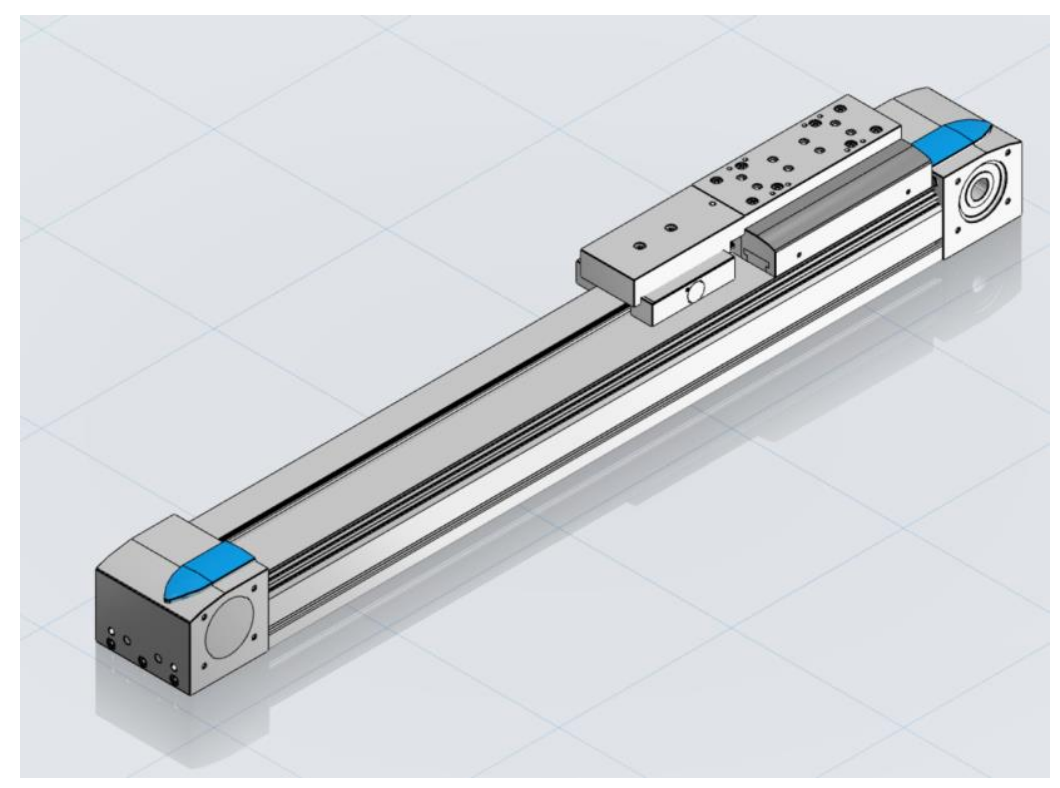

Figure 3.3. EGC-120-750-TB-GK-PNZUB positioning toothed belt axis with pneumatically released brake installed next to the carriage [2], [3] 


\subsection{Selection of the guide-ways types}

Upon the selection of the guide-ways, the necessary positional precision must be the starting point. The effector (grabber) grabs the boxes with appropriately bevelled clamps made of aluminum box sections of $30 \times 15 \times 2$ on the basis of the [8]. The grabber is grabbing the box by projecting into the factory-made $33 \times 18 \mathrm{~mm}$ grooves of the boxes intentionally designed for material handling, see Figure 3.4 .

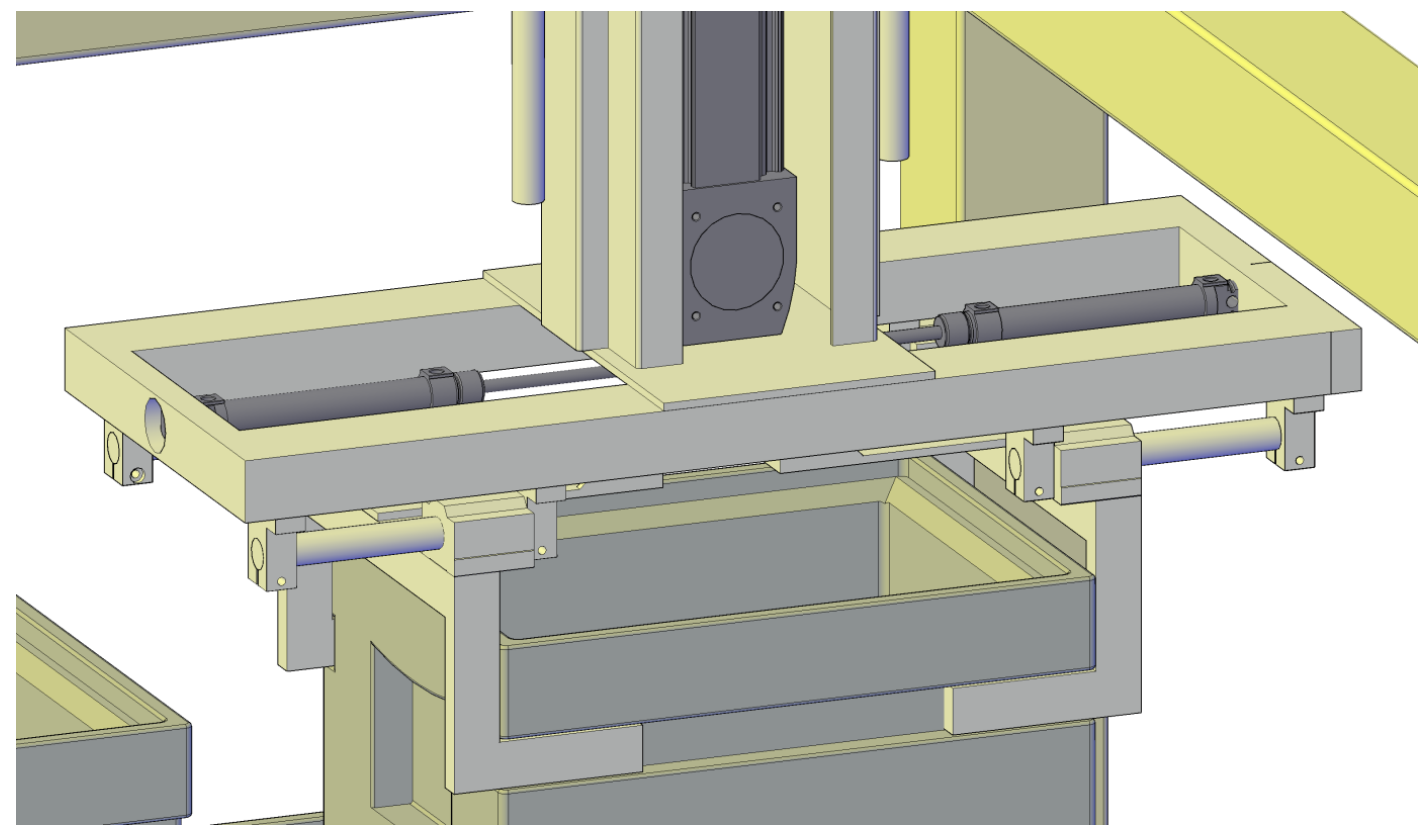

Figure 3.4. The grabber of the manipulator in the grooves of the box to be moved, with the grabbed box [8]

For the easier maintenance, sliders with built-in grease nipples are selected,

\subsection{Static verification of the guide-ways}

Upon the determination of the forces on the guide-ways and the moments, the weights from the masses of the moved elements and the useful load, which affect the rods, and the forces of inertia generated during the acceleration and deceleration of masses are considered. The forces of friction are not considered, as they are negligible compared to the other forces due to the appropriate lubrication and the small rolling resistance between the sliders and the rods. Furthermore, no oscillation analysis is made, as every new motion is initiated after the attenuation of the stopping transient phenomena due to the earlier braking. Due to the low forces of the ring mains, the application of the contact mechanics is not necessary either. By starting from all these, upon the consideration of the mass forces, it is enough to use the traditional Newton-dynamics and upon the verification of the guideways, the traditional static methods are applied. In this paper we forbear from showing the calculation in detail. 


\section{Design and set-up of the frame}

For the separate request of the client, the frame and the other construction elements had to be designed also by the ITEM machine design set. In the set, the extruded aluminum profiles can be found in a wide range of size together with the special fasteners necessary for the assembly.

\subsection{The guide of the $\mathrm{Z}$ axis}

On the basis of the functionality, the $\mathrm{Z}$ axis must be of telescopic structure. Accordingly, the $\mathrm{Z}$ axis is formed as shown by the figure below:

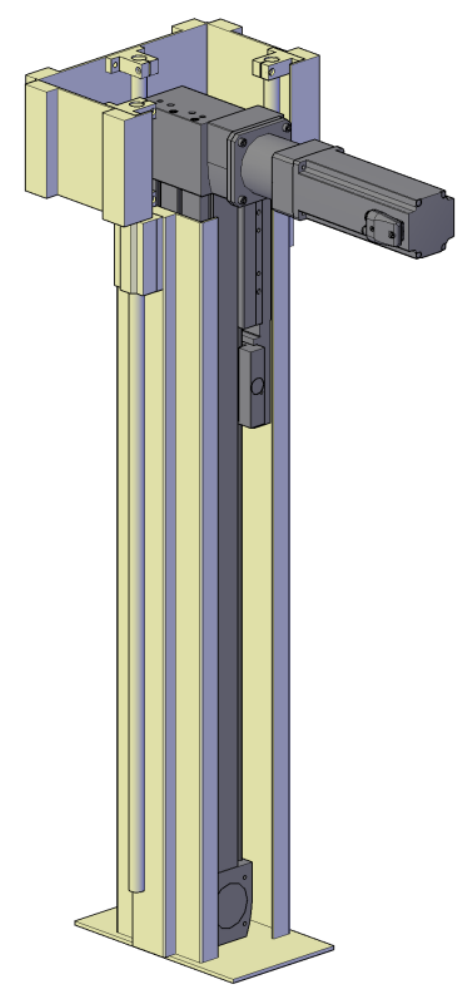

Figure 4.1. The $Z$ axis of the manipulator

In the figure, the EGC-drive-axial set-motor can be well-seen, which is surrounded by the aluminum shell structure.

\subsection{The guide of the $\mathrm{Y}$ and $\mathrm{X}$ axises}

Considering the moving elements of the axises the assembled $\mathrm{X}-\mathrm{Y}$ axis system is shown by the figure below: 


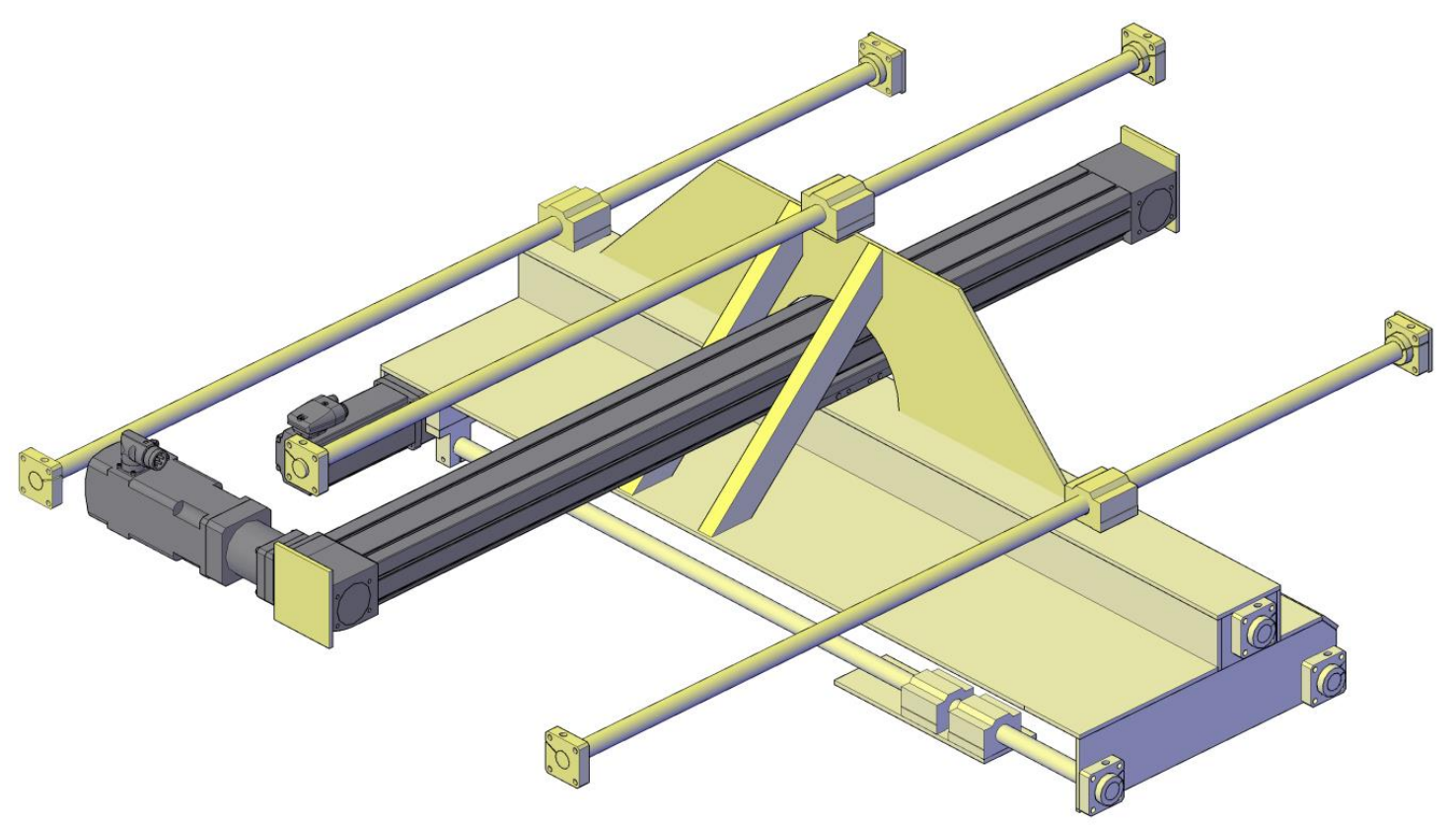

Figure 4.2. The $X$ axis with the holder structure of the $Y$ axis assembled onto the $X$ axis

\section{The handling apparatus}

The construction details of the implemented manipulator can be seen on the following figures. On the figures it may be seen that the applied ITEM machine design set must be completed with stiffening back-ups or supporting, see Fig. 5.3.

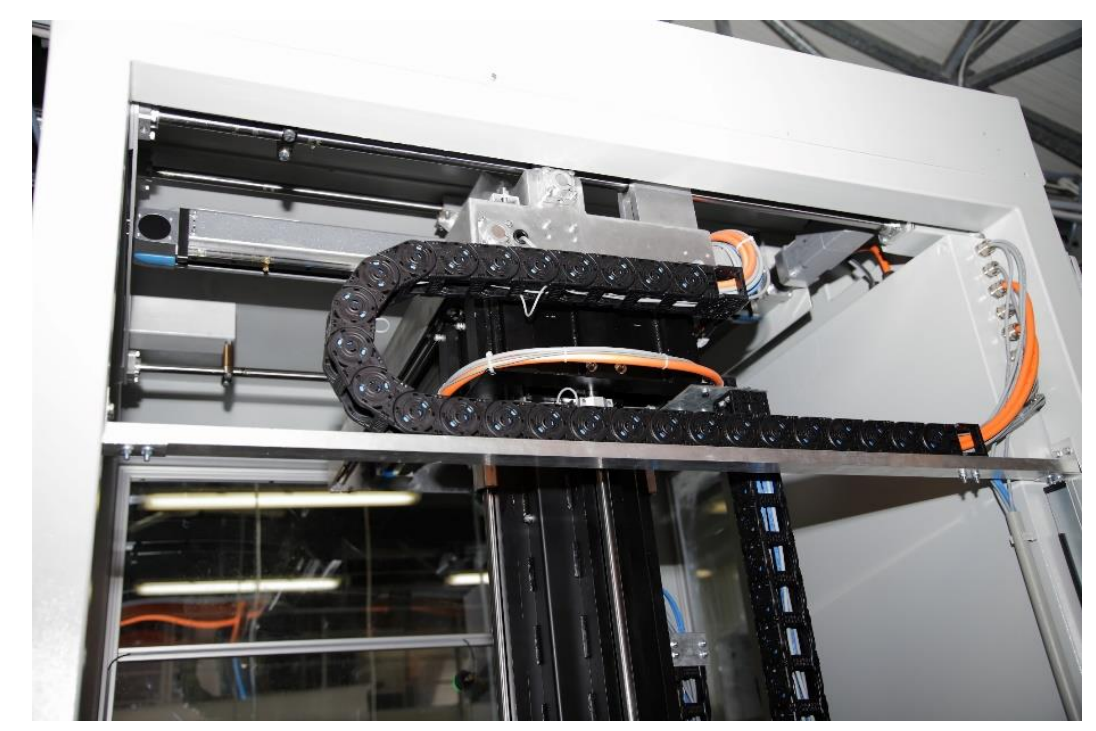

Figure 5.1. The side view of the manipulator 
International Journal of Engineering and Management Sciences (IJEMS) Vol. 4. (2019). No. 1 DOI: 10.21791/IJEMS.2019.1.40.

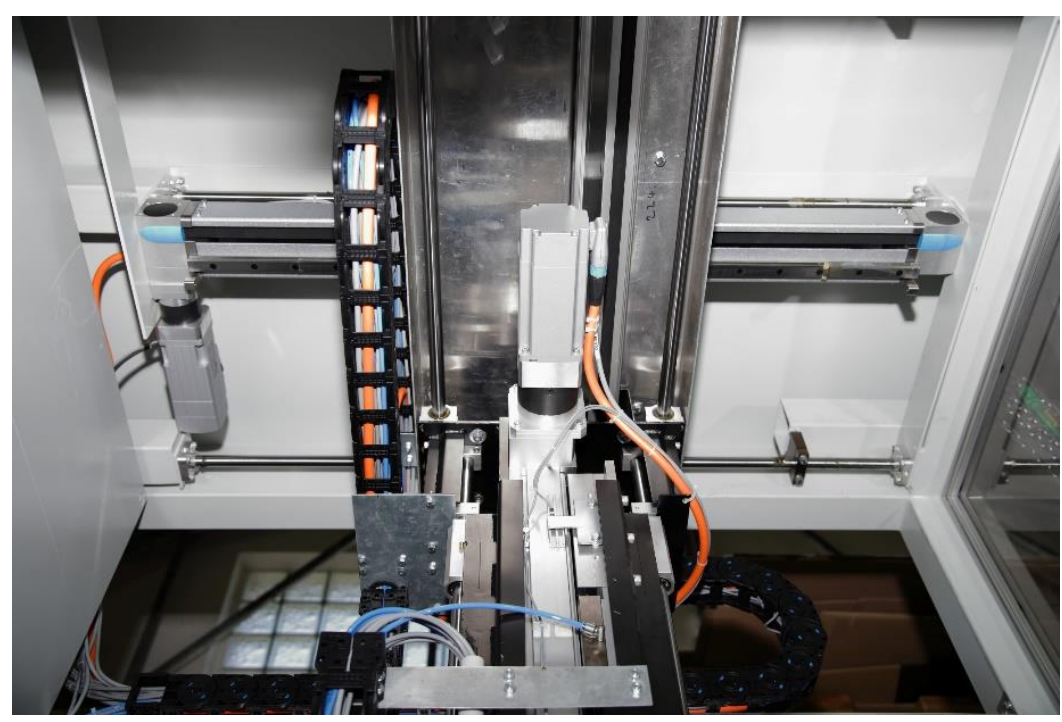

Figure 5.2. The bottom view of the manipulator inside

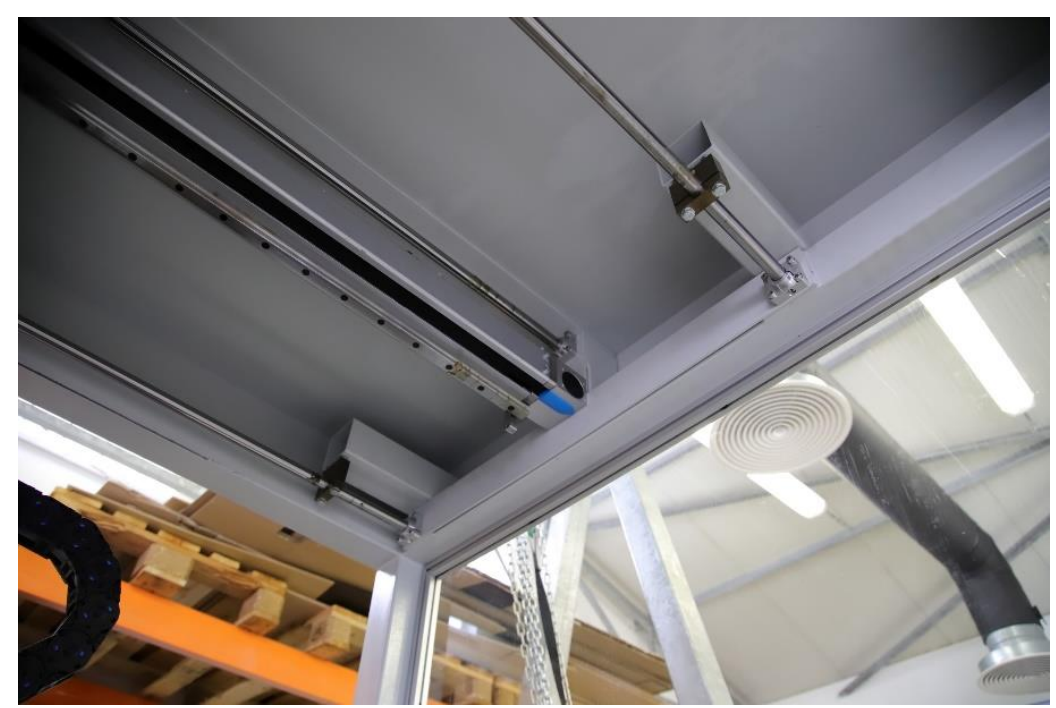

Figure 5.3. The X axis with the stiffening back-up

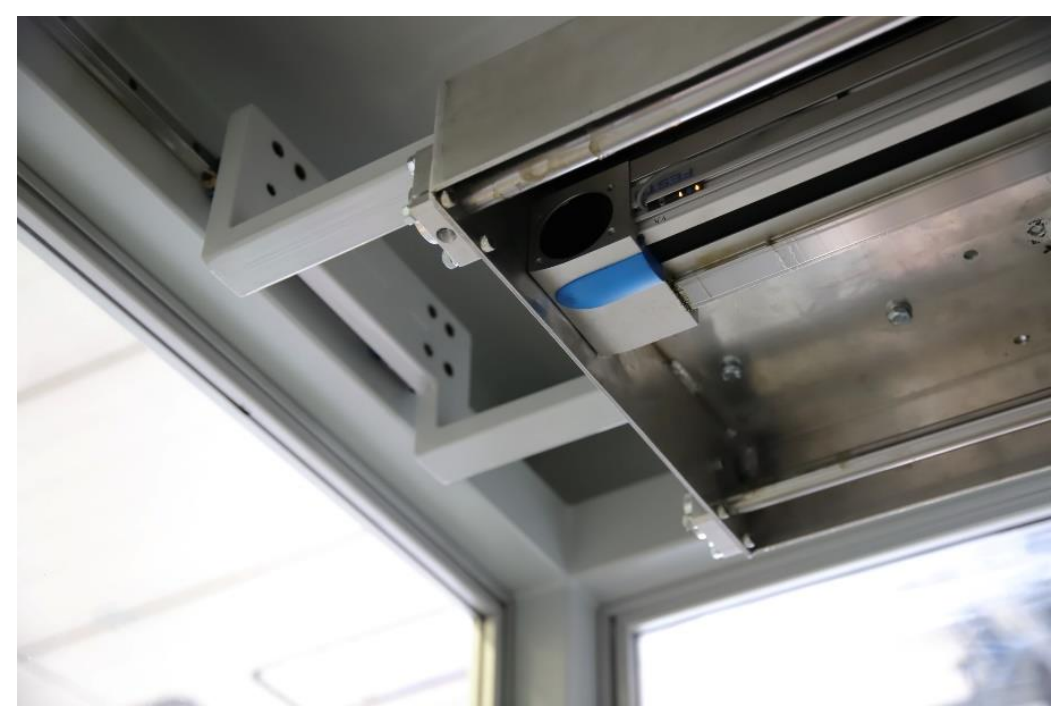

Figure 5.4. The holder structure of the $Y$ axis assembled onto the $X$ axis 332 


\section{CONCLUSIONS}

The subject of this paper is the design of a manipulator to be applied in the bearing industry. As regards the point, the manipulator has a "TTT" layout and has to load boxes. The design of the filler mechanism and the box grabber is out of the scope of this paper and the main pathway was the design of the axis system performing the loading of the boxes and that of the stand containing the axes. The elements above were inserted into the construction by using the [8].

As a basis to start from, the suitability of the machine to be inserted into a production line was focused at, i.e. it was said that regarding stroke time, the available time cannot be exceeded and the machine cannot be larger than the available space. Robustness is very important, i.e. during the life time of the device, if possible, it should require the least possible maintenance and renewal. This aim was also successfully achieved, since owing to the servo-electric drives applied, during the life time, the system practically does not require significant maintenance. The mechatronic design and execution of the system is out of the scope of this paper, however, it is noted here that the performers, the sensors and the control technology solutions eliminate the faults from the not sufficiently careful operation, thus, a machine suitable for self-surveillance and self-diagnostics was successfully designed.

The applied ITEM machine construction set assumes very careful design. In spite of the subsequent stiffening by back-up, significant amount of construction work can be saved and the machine built is of aesthetic and professional design. The rods are supplied by the supplier cut to length, therefore, significant amount of cutting work can be saved as well. Unfortunately, the mechanical machining cannot be omitted regarding the nodes and the fastening of the $\mathrm{X}$ axis.

In addition to the basic planning, the mechanical sizing and the detailed machine design execution, it is considered to be the main result of the project that with the help of the designed manipulator, significant amount of living labour demand can be saved.

As regards summary it is thought that the manipulator designed within the framework of this project is sufficient for the set task and concerning its certain characteristics (flexibility, reliability, robustness, costs) it may be a front-line device. We hope that after the inclusion of the prototype into the production line, the construction of further devices may be expected.

\section{References}

[1] www.powerbelt.hu (Powerbelt Hajtástechnikai és Kereskedelmi Kft.), 2017.

[2] FESTO Termékkatalógus (FESTO Automatizálási és Kereskedelmi Kft.), 2015.

[3] Part Data Manager v 9.08 (CADENAS GMBH, 135783 hu/en), 2017.

[4] Linear Servo Handling Systems App. v 2.06 (FESTO GMBH), 2017.

[5] Toothed belt axes EGC-TB-KF, with recirculating ball bearing guide (FESTO GMBH), 2015.

[6] Layout for Powerplant Debrecen (FAG, Schaeffler Group), 2017.

[7] KF láda és kocsi STEP modell (Frank Levin GMBH \&Co.KG), www.orgatex.com, 2017. 
International Journal of Engineering and Management Sciences (IJEMS) Vol. 4. (2019). No. 1

DOI: 10.21791/IJEMS.2019.1.40.

[8] D. Fekete-Szücs (2017) Csapágyipari manipulátor megfogó-, és töltő mechanizmusának tervezése, AFT Soft Ltd.

[9] MB Systembaukasten, ITEM Industrietechnik GmbH, Friedenstrasse 107-109., 42699 Solingen, Deutschland 2012. 